\title{
A ventral striatal-orexin/hypocretin circuit modulates approach but not consumption of food.
}

Caitlin S. Mitchell ${ }^{1,2,+}$, Simon D. Fisher ${ }^{1,{ }^{\dagger}}$, Jiann W. Yeoh ${ }^{1}$, Amy J. Pearl ${ }^{1}$, Nicholas J. Burton ${ }^{1}$, Jaideep S. Bains ${ }^{3}$, Gavan P. McNally ${ }^{2}$, Zane A. Andrews ${ }^{4}$, Brett A. Graham ${ }^{1,{ }^{\dagger}}$, Christopher V. Dayas $^{1,+, *}$

${ }^{1}$ School of Biomedical Sciences and Pharmacy, University of Newcastle, Newcastle, NSW 2308, Australia.

${ }^{2}$ School of Psychology, University of New South Wales, Sydney, NSW 2052, Australia.

${ }^{3}$ Hotchkiss Brain Institute and Department of Physiology and Pharmacology, University of Calgary, Calgary, Alberta, Canada.

${ }^{4}$ Department of Physiology, Monash University, VIC 3800, Australia.

${ }^{\dagger}$ These authors contributed equally.

* Corresponding author.

\section{Summary}

Feeding is at once both a basic biological need and a function set in a complex system of competing motivational drivers. Orexin/hypocretin neurons are located exclusively within the lateral hypothalamus (LH) and are commonly implicated in feeding, arousal, and motivated behavior, although largely based on studies employing long-term systemic manipulations. Here we show how orexin neurons in freely behaving mice respond in real time to food presentations, and how this response is modulated by differences in metabolic state and salience. Orexin neurons increased activity during approach to food, and this activity declined to baseline at the start of consummatory behavior. Furthermore, the activity of orexin neurons on approach was enhanced by manipulations of metabolic state, and increased food salience. We investigated the nucleus accumbens shell (NAcSh) as a candidate afferent region to inhibit LH orexin neurons following approach, and using projection and cell type-specific electrophysiology, demonstrated that the NAcSh forms both direct and indirect inhibitory projections to LH orexin cells. Together these findings reveal that the activity of orexin neurons is associated with food approach rather than consumption, is modulated by motivationally relevant factors, and that the NAcSh-LH pathway is capable of suppressing orexin cell recruitment.

\section{Keywords}

orexin, hypocretin, lateral hypothalamus, nucleus accumbens, feeding, approach 


\section{Introduction}

Orexin/hypocretin $(\mathrm{OX} / \mathrm{HT})$ neurons are located exclusively within the Lateral Hypothalamus (LH) with widespread projections to cortical and subcortical structures. Early work identified a role for orexin cells in waking behavior and the neurological disorder narcolepsy (España et al., 2002). Importantly, recent work supports a broadened role for these neurons in general arousal-related behaviors, including avoidance to aversive stimuli (Viviani et al., 2014). For example, orexin cell activity is strongly increased by negatively valanced emotional stimuli such as predator odor (Giardino et al., 2018). There is also a large literature linking the orexin system with drug motivated behavior, including stress- and cue-evoked drug-seeking as well as the behavioral and physiological syndrome associated with opiate withdrawal (Georgescu et al., 2003).

An important question regarding orexin function is whether these neurons are also recruited by positively valanced emotional stimuli such as food and how this activity might be influenced by changes in metabolic state. Moreover, it remains unclear whether this activity is linked with approach versus consummatory actions. Support for orexin cell activity related to consummatory behavior was demonstrated in early work that showed that intracerebroventricular injections of the peptide increased food intake and body weight (Sakurai et al., 1998). However, more recent studies in which ablation of orexin neurons using genetically targeted diphtheria toxin paradoxically increased body weight (Ramanathan \& Siegel, 2014), and measures of cell activity in vivo demonstrated that the orexin cells are rapidly inactivated by eating irrespective of caloric content or metabolic state (González et al., 2016). These findings led us to conclude that it is consummatory action that abruptly suppresses orexin neuron activity.

A candidate brain region with capacity to inhibit orexin activity is the nucleus accumbens shell (NAcSh). Activation of NAcSh terminals in the LH suppresses food and alcohol seeking behavior (Gibson et al., 2018; O'Connor et al., 2015). However, no synaptic connections on to orexin neurons in the LH were observed (O'Connor et al., 2015). This lack of connectivity was concluded through assessments of LH cell phenotype, including orexin neurons, using neurobiotin filling and post-hoc immunolabelling, an approach we have found to be prone to false-negative detection (Yeoh et al., 2012).

To resolve the continued uncertainty surrounding the role of the orexin system in approach versus consummatory actions, we assessed the reactivity of orexin neurons to palatable or normal food using in vivo fiber photometry under different metabolic states. These recordings revealed three key findings. First, that GCaMP6-mediated activity signals of orexin cells decreased abruptly before consummatory actions of normal, palatable, or ghrelin-influenced food. Second, under food restriction the presentation of normal chow induced a significantly larger activity response than in 'ad libitum' mice, as did normal chow

following injection of ghrelin. Third, the presentation of a palatable chocolate reward to fed mice increased HT/OX activity to levels identical to food restricted or ghrelin-injected mice. We next confirmed that optogenetic activation of NAcSh terminals in the LH disrupts feeding behavior, and then investigated circuits governing orexin cell recruitment from the NAcSh. Slice electrophysiology recordings revealed both direct and indirect NAcSh projections to orexin cells, thereby identifying a functionally patent pathway with the capacity to suppress orexin cell recruitment. 


\section{Results}

\section{Metabolic state and palatability can enhance the activity of HT/OX cells}

Orexin-Cre mice were injected with Cre-dependent AAV5-GCaMP6f virus into the perifornical-lateral hypothalamic area (herein referred to as $\mathrm{LH}$ ) and implanted with a fiber optic cannula $0.2 \mathrm{~mm}$ dorsal to the LH (Fig. 1A). In mice used to verify the specificity of the virus, GCaMP6f labelling was visualized in the LH consistent with the known distribution of orexin neurons (Peyron et al., 1998). Importantly, approximately $97 \%$ of all GCaMP6f transduced cells were dual labelled for orexin-A and 53.5\% of HT/OX-positive LH cells were GCaMP6 positive (Fig. 1B-C), demonstrating that our mouse line can selectively express GCaMP6f in HT/OX neurons.

To study $\mathrm{Ca}^{2+}$ based activity dynamics in HT/OX neurons under different metabolic states, orexin-Cre::DIO-GCaMP6f mice were tested with the presentation of standard food (chow) placed into their home cage under three metabolic conditions (Fig. 1D) - ad libitum fed + normal chow ('ad libitum' condition); $24 \mathrm{~h}$ fasted + normal chow ('food restricted' condition); ad libitum fed + injections of the appetite promoting hormone + normal chow ('ghrelin' condition). We also investigated the approach to a palatable chocolate food pellet in ad libitum fed animals (a mini chocolate $M \& M^{\mathrm{TM}}$, 'palatable' condition). Mice were exposed to all conditions in a counterbalanced design. A significant reduction in latency to approach the food was found in all conditions, in comparison to the ad libitum fed condition (Fig. 1E). Latency to approach in the food restricted, ghrelin injected, and palatable conditions did not differ. During approach to the test food item, $\mathrm{Ca}^{2+}$ activity in orexin neurons increased from baseline in all groups, irrespective of metabolic state (examples Fig. 1F; mean signals Fig. 1G). The peak amplitude of the $z-d F / F$ signal during the approach period (from first approach to start eating) varied significantly by condition, and the food restriction condition had a significantly higher mean amplitude (Fig. $\mathbf{1 H}$ ). Additionally, the food restriction and palatable conditions exhibited a significantly larger area under the curve $(A \cup C)$ of the $\mathrm{Ca}^{2+}$ signal during approach than the ad libitum group. Although ghrelin injections tended to increase orexin cell activity to food restriction or palatable condition levels, this increase did not reach significance. Together these data suggest both metabolic state and palatability can enhance the activation of orexin cells. Importantly, a close inspection of the temporal profile of orexin cell activity indicated that GCaMP6f fluorescence was closely linked to food approach rather than consummatory actions - the signal peaked during approach, prior to food consumption, and returned to baseline levels during consumption (Fig. 1F).

\section{NAcSh projections to the LH control food consummatory and approach behaviours}

We posited that the NAcSh could be an afferent structure that modulates LH orexin cell activity with respect to food approach and consumption. In support, activation of terminals in the LH that originate from the NAcSh inhibited food and alcohol seeking (Gibson et al., 2018; O'Connor et al., 2015). To confirm that activation of NAcSh terminals in the LH would suppress food consumption in the orexin-Cre mice and our behavioral model we injected AAV-ChR2-YFP or AAV-YFP into the NAcSh, and implanted fiber optic cannulae above the LH (Fig. 2A). The AAV-Chrimson-tdTomato construct was also used instead of ChR2 in some animals, and results were pooled (see Fig. 2). Optogenetic stimulation produced a significant disruption of feeding, measured as a reduced latency to terminate feeding (Fig. 2B). ChR2-YFP and Chrimson mice also displayed a significant increase in locomotor activity 
(Fig. 2C). Together these data confirm that optogenetic activation of NAcSh $\rightarrow$ LH terminals can disrupt consummatory actions, like previous reports (Gibson et al., 2018; O'Connor et al., 2015).

\section{ChR2-assisted circuit mapping of NAcSh inputs to LH orexin neurons}

Activation of orexin neurons was highest during food approach, and optogenetic stimulation of NAcSh terminals in the LH disrupted consummatory actions. Therefore, we asked whether NAcSh terminals might influence LH orexin cells. To address this question, we prepared Vgat-Cre mice with NAcSh-directed injections of AAV5-DIO-ChR2-YFP, and AAV8-h-orexin-tdTomato into the LH to visualize orexin neurons (Fig. 3A-B; see Supp. Fig. 1 for colocalization with orexin-A labelling). Whole-cell patch clamp recordings were then made from tdTomato expressing cells (see Supp. Fig. $\mathbf{2}$ for recording site locations). Photostimulation of ChR2-expressing terminals produced inhibitory currents in tdTomatoexpressing orexin neurons (18 out of 33 total recorded orexin cells; Fig. 3C). 75\% of these photocurrents were insensitive to TTX, indicative of monosynaptic connections (Fig. 3D). The remaining $25 \%$ of recorded responses were sensitive to TTX, consistent with monosynaptic connections (Fig. 3D-E). The mean amplitude of IPSCs did not differ significantly between projection types (Fig. 3F), while monosynaptic IPSCs exhibited significantly faster latencies than polysynaptic responses (Fig. 3G), consistent with their profiles. These findings indicate that there are robust monosynaptic and polysynaptic inhibitory NAcSh projections on to LH orexin neurons (Fig. $\mathbf{3 H}$ ). 


\section{Figures}

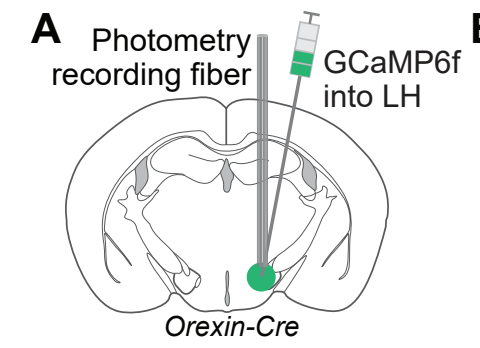

D
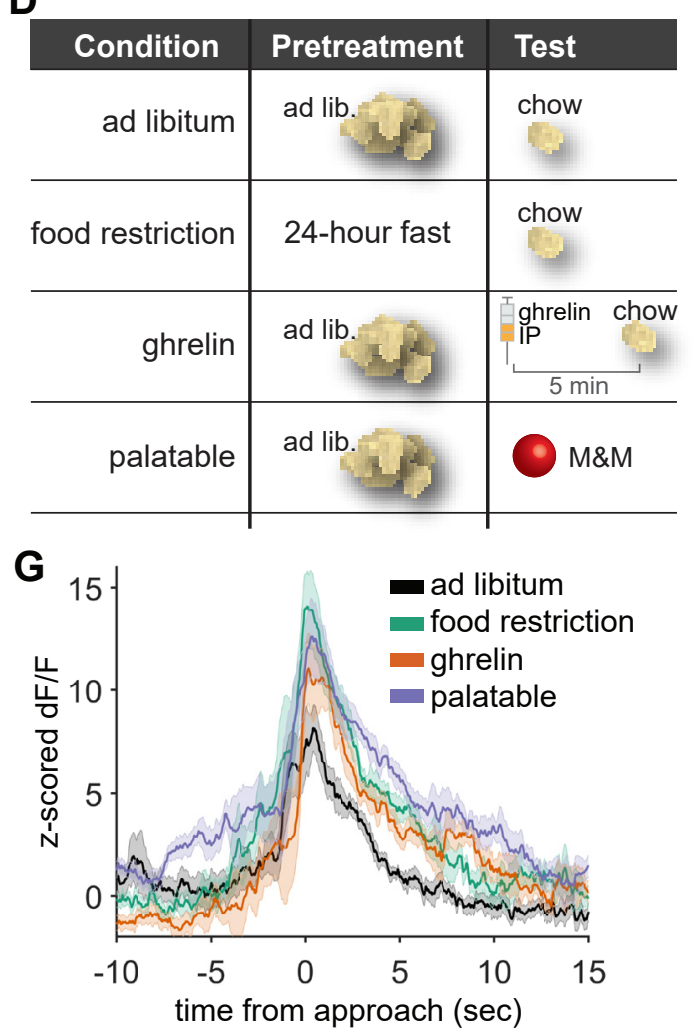

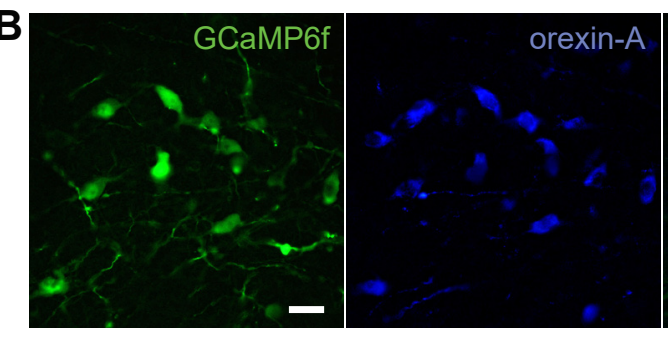

E

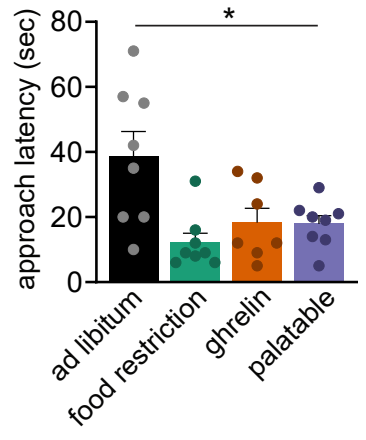

H

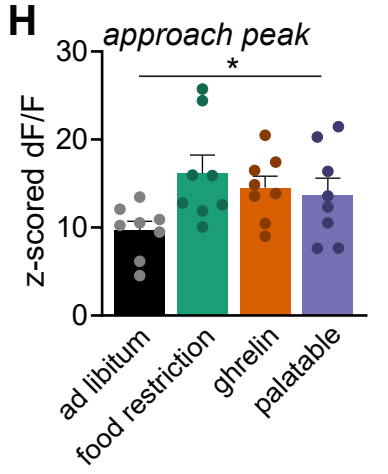

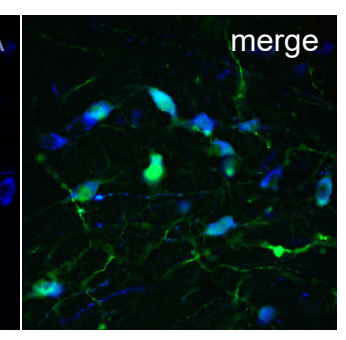

Orexin-A of GCaMP6 Orexin-A of GCaMP6 GCaMP6 of Orexin-A (n)

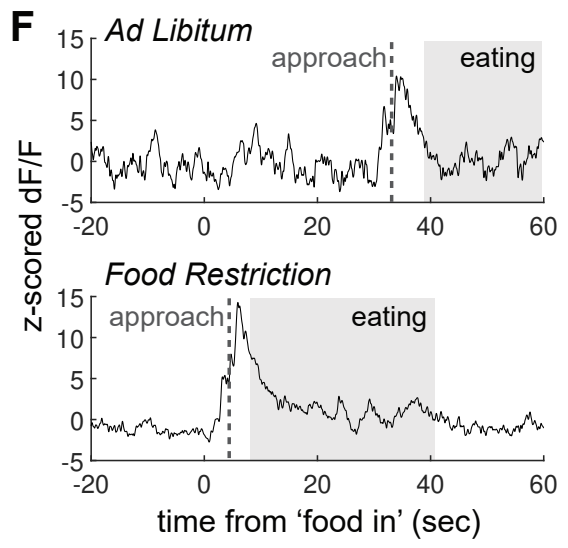

I

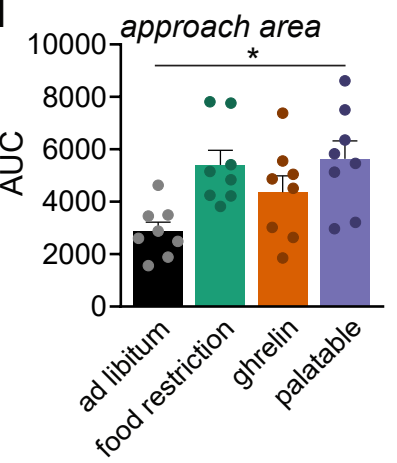

Figure 1. LH orexin neurons respond on approach to food objects, modulated by metabolic state.

(A) Orexin-Cre mice had LH-directed injections of DIO-GCaMP6f and implantation of a fiber optic probe. (B) Microscopy images showing Orexin-Cre dependent GCaMP6f expression in the LH, together with immunolabelling of orexin-A (AMCA) positive cells, and a merged image. (C) Proportion of GCaMP6 + cells that are Orexin-A+ $(93 \%, \pm 1.8 \%, N=4$ mice), and Orexin-A+ cells that are GCaMP6+ (54\% $\pm 7.2 \%)$. (D) Experimental groups, with their pretreatments and test configurations. (E) The latency to approach the food pellet was significantly different between groups (RM one-way ANOVA, $F_{3,20}=7.46, P=0.001$ ). Multiple comparisons testing revealed that each group had a significantly lower approach latency compared to ad libitum ( $P<0.01$ for each), and no significant differences between food restriction, ghrelin, and palatable groups $(P>0.7$ for each). (F) Example z-scored dF/F photometry traces for the Ad Libitum and Food Restriction conditions. (G) Mean z-dF/F traces and shaded SEM region for each condition, centered around the time of first approach to food. (H) The peak amplitude of the $z-d F / F$ signal during the approach period varied significantly by treatment condition (RM one-way ANOVA, $F_{3,21}=3.1, P=0.04$ ), with multiple comparisons showing a significant difference between 'ad libitum' vs. 'food restriction' (Dunnett's test, $P=0.006$ ). (I) Area under the curve (AUC) analysis of the approach period also significantly varied by treatment condition (RM one-way ANOVA, $F_{2,15}=4.5, P=0.02$ ), with multiple comparisons showing significant differences between 'ad libitum' vs. 'food restriction' $(P=0.006)$, and 'ad libitum' vs. 'M\&M' ( $P=0.03)$. Error bars = SEM. Scale bars: $25 \mu \mathrm{m}$. 
A

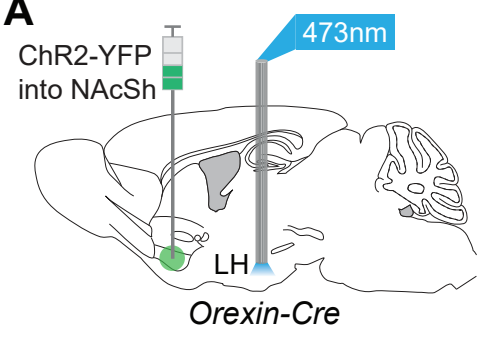

B

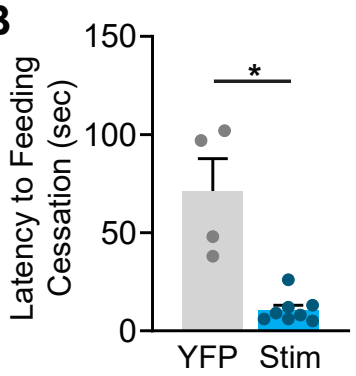

C

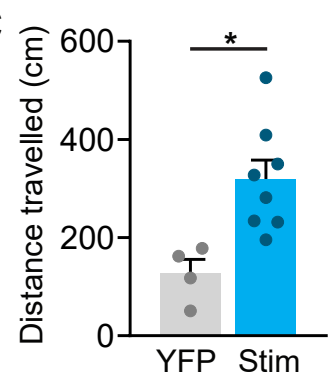

Figure 2. Optogenetic stimulation of NAcSh fibers in the LH terminates palatable food consumption.

(A) Orexin-Cre mice had NAcSh injections of ChR2-YFP or Chrimson-tdTomato, or a YFP control virus, and a fiber optic probe in the LH. At the start of food consumption, NAcSh fibers in the LH were stimulated with a $473 \mathrm{~nm}$ pulse train $(20 \mathrm{~Hz}, 10 \mathrm{~ms}$ pulse width, $15 \mathrm{~mW})$ for 30 seconds on 30 seconds off, over 5 minutes total. Chrimson-expressing mice were stimulated with $620 \mathrm{~nm}$ pulses with the same properties. (B) Optical stimulation ('Stim') caused a rapid cessation of feeding, which was significantly different to controls ( $t$ test, $P=0.0087, n=8$ ). (C) The distance travelled in the home cage during photostimulation was significantly increased in ChR2 animals (t test, $\mathrm{P}=0.0167$ ). Latencies and Distances Travelled by Chrimson-injected mice did not vary significantly from ChR2injected mice ( $t$ tests, $\mathrm{P}=0.3$ and 0.29 respectively), and hence were combined. 
A
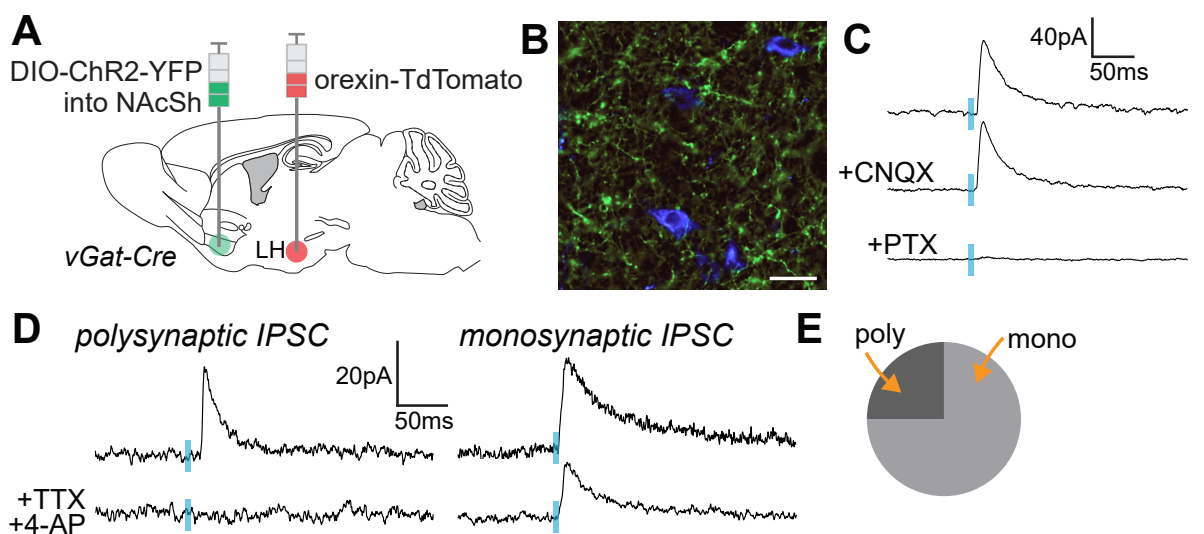

E poly

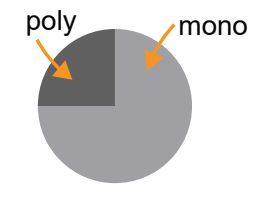

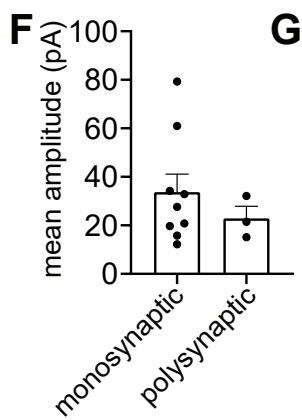

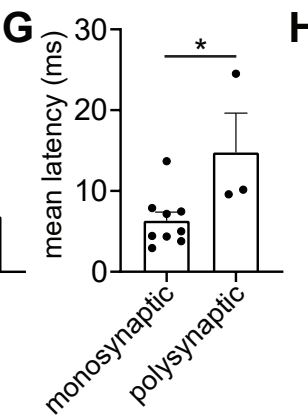

H polysynaptic pathway
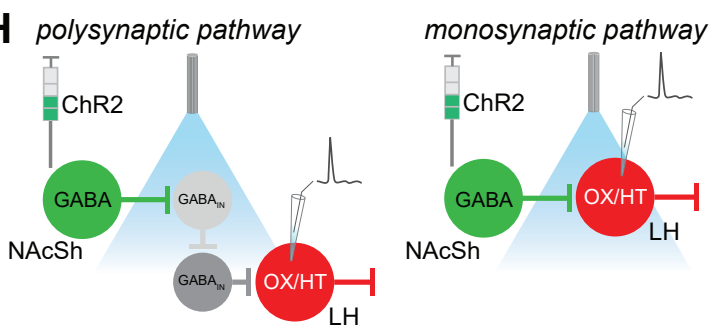

\section{Figure 3. The NAcSh projection to orexin cells in the LH comprises both mono and polysynaptic inhibitory projections.}

(A) Slices were prepared from Vgat-Cre mice with ChR2-YFP injections in the NAcSh, and orexinTdTomato in the LH to label orexin-positive cells, which can be seen (B) in blue surrounded by YFP+ fibers from the NAcSh. (C) Whole field stimulation of NAcSh fibers induced IPSCs in orexin cells held at $-40 \mathrm{mV}$ that were insensitive to CNQX (competitive AMPA/kainate receptor antagonist), and abolished by picrotoxin (PTX; GABA channel blocker), indicative of inhibitory currents. (D) Application of TTX and 4-AP was used to determine if the IPSC was polysynaptic or monosynaptic. Representative examples of poly and monosynaptic IPSCS are presented. (E) Three quarters of the recorded cells exhibited monosynaptic IPSCs, and a quarter polysynaptic. (F) The mean amplitude of IPSCs was not significantly different between projection types. (G) The mean latency from photostimulation to the onset of the IPSC was significantly reduced in monosynaptic IPSCs (unpaired $t$ test, $P=0.02$ ). (H) Diagram of proposed pathways of polysynaptic and monosynaptic projections from the NAcSh to the LH. NAcSh = Nucleus accumbens shell. $\mathrm{LH}=$ Lateral hypothalamus. GABA $\mathrm{IN}_{\mathrm{N}}=$ GABAergic interneuron. 


\section{Discussion}

We used a combination of circuit dissection techniques including cell type-specific fiber photometry to show that the activity of LH orexin neurons is modulated by metabolic state as well as the palatability or salience of food. We found that LH orexin cell activity peaks on approach to food, and then decreases during consummatory behavior. We investigated the NAcSh as a candidate area that could be capable of suppressing orexin activity, for instance, following approach to food. Our findings demonstrated that broad optogenetic activation of NAcSh terminals in the LH disrupted ongoing behavior. Notably, projection-specific electrophysiology identified mono and polysynaptic inhibitory connections between the NAcSh and orexin neurons. In summary, this data reveals new information about orexin activity in real time and implicates projections from the NAcSh in an inhibitory role over LH orexin circuits.

\section{Orexin cell activity is associated with approach to food}

Using fiber photometry targeted at LH orexin cells we showed that this population primarily responds to food approach. GCaMP6f fluorescence declined following approach to food, which is consistent with previous research that implicated orexin neurons in rewardseeking and motivation for sweet food (Harris et al., 2005; Thorpe et al., 2005), and increased arousal and locomotor behavior (Alexandre et al., 2013). It has also been shown that food restricted mice exhibit increased c-Fos activity in orexin neurons following food anticipation (Mieda et al., 2004).

Notably, we found limited evidence for changes in $\mathrm{Ca}^{2+}$ fluorescence during food consummatory actions. This finding appears to be contrary to earlier work linking orexins with increases in food intake (Sakurai et al., 1998). More recent work has suggested that the increases in food consumption may be secondary to enhanced behavioral arousal and locomotion, such as produced by high orexin peptide injections (Blais et al., 2017; Nevárez \& Lecea, 2018; Sutcliffe \& Lecea, 2002; Zink et al., 2017). In keeping with this line of thinking, the deletion of orexin cells using viral-mediated diphtheria toxin increased food consumption and weight gain (González et al., 2016).

A report studying the $\mathrm{Ca}^{2+}$ activity of orexin neurons found that activity rapidly declined after contact with foods of different tastes, textures and nutrient content (González et al., 2016). Indeed, the authors argued that the act of eating rapidly inactivates orexin neurons. This interpretation was supported by the timescale of effects of food contact or licking on $\mathrm{Ca}^{2+}$ activity dynamics in orexin neurons making direct inhibitory actions of nutrients (such as glucose) on orexin cell firing unlikely. In the present study we did not detect a rapid reduction in activity in orexin cells during eating, regardless of metabolic state or palatability, but rather the reduction in orexin cell activity was more closely correlated with the termination of approach behavior.

\section{Orexin activity during approach to food is modulated by metabolic state and salience}

Interestingly, orexin neurons displayed greater $\mathrm{Ca}^{2+}$ activity depending on metabolic state. For example, food restriction significantly increased $\mathrm{Ca}^{2+}$ activity to standard chow. Enhanced orexin signaling in these conditions is consistent with work of Horvarth and Gao (2005) who showed that food restriction was sufficient to increase the frequency of miniature excitatory postsynaptic currents and increase Vglut2-positive puncta onto orexin neurons. One interpretation of these findings is that food restriction increases orexin 
excitatory drive to increase food-seeking and approach motivation. Notably, we also found that injections of ghrelin tended to elevate orexin cell activity to levels seen under food-deprivation, even though the animals were allowed free access to food. Ghrelin is a peptide secreted by the stomach that is thought to stimulate feeding behavior through actions on growth hormone secretagogue receptors (GHSR)-expressing neurons in the arcuate nucleus (Hewson et al., 2002). Ghrelin can also increase orexin activity in electrophysiological slice or dispersed cell preparations, indicating possible direct effects in the LH (Kohno et al., 2003). We also found that the orexin cell responses to palatable food reached levels equivalent to when animals had been food restricted. Thus, not only does metabolic state influence orexin cell activity but so does approach to a more salient food object.

Our work is also consistent with behavioral studies showing that orexin receptor antagonists reduced motivated responding for palatable food (Borgland et al., 2009) and drugs of abuse under high effort progressive ratio conditions (James et al., 2011).

Furthermore, drug-induced increases in excitatory drive to orexin neurons promotes reward-seeking behavior but has little impact on drug consumption (Bentzley \& AstonJones, 2015). Together, this data suggests that the orexin system acts to enhance effortbased approach and avoidance behavior according to the valance of the stimulus and that the level of activity can be updated through actions from metabolic signals and synaptic drive.

\section{The NAcSh provides inhibitory inputs to orexin neurons and may prevent approach to palatable food}

The termination of activity after food approach raised a key question as to the possible brain regions might inhibit orexin activity. We focused on the NAcSh, given prior work showing that inhibitory inputs from the ventral striatum can terminate feeding-related behaviors and alcohol-seeking (Gibson et al., 2018; O'Connor et al., 2015). Like these reports, we found that optogenetic activation of NAcSh terminals in the LH caused animals to abort feeding behavior. NAcSh terminal stimulation also induced a dramatic increase in locomotor behavior and home cage investigation. This behavioral repertoire resembled actions evoked if the animal was disturbed from eating by a potential threat.

Using Vgat-Cre mice and virally mediated expression of the reporter protein tdTomato, we found evidence of mono and polysynaptic inhibitory connections to orexin cells. These findings provide the first evidence of functionally patent connections from the NAcSh to LH orexin cells. It is important to highlight that these observations differ from previous work demonstrating that NAcSh D1R spiny projection neurons make little to no contact onto orexin (or MCH)-expressing cells in the LH (O'Connor et al., 2015). In that study, the assessment of $\mathrm{NAcSh} \rightarrow \mathrm{LH}$ connectivity onto orexin cells within the $\mathrm{LH}$ was made using blind patch recordings. To identify the phenotype of recorded neurons and assess the connectivity of orexin or $\mathrm{MCH}$-expressing neurons the authors used neurobiotin filling and post-hoc immunolabelling. From our experience, this approach tends to result in a large rate of false-negative outcomes - possibly owing to peptide degradation during the electrophysiological recording (Yeoh et al., 2012).

The precise connectivity within the LH that permits indirect polysynaptic inhibitory actions remains to be fully understood but is likely a consequence of the complex local LH circuitry that gates the output of orexin neurons. For example, orexin neurons receive input 
from local excitatory and inhibitory interneurons (Ferrari et al., 2018; Xie et al., 2006). Further work will be required to determine whether the indirect inhibition of orexin cells involves disinhibition of a local GABA microcircuit or inhibition of local glutamatergic interneurons.

Overall, the present study demonstrates that the activity of orexin neurons precedes food consumption and is tightly associated with appetitive approach behavior rather than consummatory actions. The activity of orexin neurons is also enhanced by metabolic state and as well as the salience of food. Therefore, orexin neurons appear involved in appetitive approach behavior, independent of actual food intake. Electrophysiological patch-clamping of LH orexin neurons demonstrate that the NAcSh sends indirect and direct inhibitory signals to orexin neurons. Future studies will need to determine exactly how these pathways control LH microcircuits to gate approach and other behaviors. Understanding how these pathways are disrupted under pathological states such as obesity or addiction may highlight new insights into treating these conditions using behavioral or pharmacological interventions. 


\section{Methods}

\section{Lead contact and material availability.}

This study did not generate new unique reagents. Further information and requests for resources and reagents should be directed to and will be fulfilled by the Lead Contact, Chris Dayas (christopher.dayas@newcastle.edu.au).

\section{Subjects}

Knock-In Orexin-IRES-Cre (orexin-Cre) mice were obtained from BIDMC Neurology (Harvard Medical School). Mice were hemizygous. For electrophysiology experiments, Vgat-IRES-Cre (Vgat-Cre) mice were obtained from Jackson laboratory (JAX \#028862). Mice were aged 8 to 14 weeks old at the start of experiments, and littermates were randomly assigned to experimental groups.

Mice were housed in a $12 \mathrm{~h}$ light/12 $\mathrm{h}$ dark cycle in a temperature-controlled $\left(21^{\circ} \mathrm{C}\right)$ and humidity-controlled (50\%) environment. Mice were not food or water restricted for any experiment, apart from the 24-hour fast in the 'food restriction' condition. Mice in fiber photometry and optogenetic experiments relating to Fig. 1 and 2 were individually housed, whereas Vgat-Cre mice relating to Fig. 3 were group housed.

The following conditions were used in photometry and optogenetic stimulation experiments:

C1: Ad libitum: animals were allowed ad libitum access to chow leading up to testing. The test food was a normal chow pellet.

C2: Food restriction: animals were not allowed access to their home caged chow for 24 hours prior to testing. The test food was a normal chow pellet.

C3: Ghrelin IP: animals were allowed ad libitum access to chow leading up to testing. The test food was a chow pellet.

C4: Palatable food: animals were allowed ad libitum access to chow leading up to testing. The test food was a mini chocolate M\&M.

All experiments were conducted according to the ethical guidelines approved by the University of Newcastle Animal Care \& Ethics Committee.

\section{Surgery}

To validate the selectivity of viral expression in orexin-Cre mice $(n=4)$, they received unilateral Cre-dependent viral injections of AAV5-CAG-FLEX-GCaMP6f directed at the LH (0.3ul; AP: -1.4, ML: -1.0, DV: -5.25).

For fiber photometry experiments, orexin-Cre mice $(n=8)$ received unilateral injections of AAV5-CAG-FLEX-GCaMP6f directed at the LH (0.3ul; AP: -1.4, ML: -1.0, DV: -5.25). During the same surgery, fiber optic probes $(6 \mathrm{~mm} ; 400 \mu \mathrm{m}$ core; Metal Ferrule Cannula (MF2.5); 0.37 NA; Doric Lenses, QC, CAN) were also inserted just above the LH (AP: -1.4, ML: -1.0, DV: 5.1).

For optogenetic stimulation experiments, orexin-Cre animals $(n=8)$ received an AAV5-hSynChR2-YFP virus or an AAV5-hSyn-YFP directed to the NAcSh (0.3ul; AP: +1.4, ML: -0.85, DV: 4.85). A fiber optic probe was inserted just above the $\mathrm{LH}(6 \mathrm{~mm} ; 400 \mu \mathrm{m}$ core; Metal Ferrule Cannula (MF2.5); 0.37 NA; Doric Lenses, QC, CAN; AP: -1.4, ML: -1.0, DV: -5.1). 
For electrophysiology experiments, Vgat-Cre mice received viral injections directed at both the NAcSh and LH. For the NAcSh, bilateral injections of AAV5-Ef1a-DIO-hChR2(H134R)-EYFP $(0.3 \mu \mathrm{l} /$ hemisphere; AP: +1.4, ML: +/- 0.85, DV: -4.9) were performed and animals were allowed to recover. Two weeks later, AAV8-h-orexin-tdTomato was injected bilaterally into the LH for visualization of orexin neurons during slice recordings $(0.2 \mu \mathrm{l} /$ hemisphere; AP: 1.4, ML: +/- 1.0, DV: $-5.25 ; 2.23^{13} \mathrm{vg} / \mathrm{ml}$ ). This virus was diluted 1:4 in sterile saline solution before stereotaxic injection. 2 weeks following $h$-orexin injections, mice were sacrificed for electrophysiological experiments.

\section{Fiber Photometry}

To visualize $\mathrm{Ca}^{2+}$ fluorescence using single fiber photometry; a PC running Doric Lenses Software (Doric Neuroscience Studio version 5.3.3.1) was connected to a Fiber Photometry Console (FPC; Doric Lenses, QC, CAN). The FPC was attached via a BNC to a 4-channel LED Driver. A 465nm wavelength LED (CLED; Doric Lenses) was used to stimulate GCaMP and reflected light was detected in the $525 \mathrm{~nm}$ spectrum using a filter cube consisting of dichroic mirrors (6-port Fluorescent Mini Cube with an integrated photodetector head; iFMC; Doric Lenses). A 405nm LED (CLED; Doric Lenses) was used as an isosbestic control, as fluorescence detected from this wavelength is not $\mathrm{Ca}^{2+}$ dependent, so hence changes in signal can be attributed to autofluorescence, bleaching and fiber bending. Light from these fiber-coupled LEDs entered the filter cube via FCM-FCM patch cords ( $200 \mu \mathrm{m}$ core; $0.22 \mathrm{NA}$; Doric Lenses). Light exited the filter cube via a FC-MF2.5 patch cord ( $400 \mu \mathrm{m}$ core; $0.48 \mathrm{NA}$; Doric Lenses). Animals were attached to this patch cord via the implanted fiber optic cannula with cannula and patch cord communicating via a plastic mating sleeve (Thorlabs). Emission light from the animal is transmitted back up through the same patch cord. A lockin amplifier (Doric Lenses) was used to modulate the signals. Power output from the end of the FC-MF2.5 patch cord was determined using a photodiode power meter (Thorlabs, NJ, USA). Power output from both LEDs was set at approximately $40 \mathrm{uW}$, with power never exceeding 60uW.

Animals were habituated in their home cage to the test set-up for 3 days prior to testing (15 minutes/day; including patch cord connection). Each animal underwent the four separate test conditions: C1: Ad libitum, C2: Food restriction, C3: Ghrelin, and C4: Palatable. The tests were counterbalanced for animals to account for order effects. Test days were separated from each other by 2 or 3 days. For C1, C2 and C3 animals were first attached to the patch cord and habituated for 5 minutes and GCaMP6f fluorescence recorded for 5 minutes. At the 5-minute mark, the appropriate food pellet was placed at the opposite side of the home cage to where the animal was located. For C3: Ghrelin IP, animals were given a 5-minute baseline recording and were given a saline control injection to account for any hyperarousal effects of IP injection. 10 minutes later, animals were injected with $0.3 \mathrm{mg} / \mathrm{kg}$ of ghrelin and 5 minutes later a normal chow pellet was placed in the home cage.

\section{Photometry Analysis}

Doric Photometry traces were synchronized with the live video recording (Blackfly S GigE, FLIR systems, USA) in order to determine event times: approach to food, begin eating, stop eating. The demodulated output from two channels (isosbestic control $405 \mathrm{~nm}$ and $\mathrm{Ca}^{2+}$ dependent $465 \mathrm{~nm}$ wavelengths) was exported from the Doric Neuroscience Software. All analysis was performed using custom MATLAB scripts. $465 \mathrm{~nm}$ and $405 \mathrm{~nm}$ signals were first averaged with a sliding window, then baseline correction was performed using the adaptive 
iteratively reweighted penalized least squares method (Zhang et al., 2010). Next, robust zscores were calculated for both signals ((signal - median) / median absolute deviation). The isosbestic signal was then aligned to the $\mathrm{Ca}^{2+}$-dependent signal using linear regression (MATLAB's lasso function). Finally, the fitted isosbestic signal was subtracted from the $\mathrm{Ca}^{2+}$ dependent signal to give the $z$-score $d F / F$ values.

The peak $z-d F / F$ value during the approach was measured as the maximum value during the period from 5 seconds prior to 'first approach' identified by video observation, until the 'begin eating' event. This maximum value was baseline corrected with a baseline measure comprising the mean of 5 seconds of activity prior to food presentation. Area under the curve was measured using the MATLAB trapz function, of the same time period.

\section{Optogenetic stimulation}

Mice were connected to patch cords (400 $\mu$ m core; FC-MF2.5; 0.48 NA; Doric Lenses, QC, CAN) in their home cage and allowed to habituate for 5 minutes. The opposing end of the patch cord was connected to a FC-FC fiber optic $1 \times 1$ rotary joint (Doric Lenses). A $473 \mathrm{~nm}$ DPSS laser (Laserglow Technologies, ON, CAN) was used to deliver light into the rotary joint via a patch cord with FC/PC connections on each end. Laser parameters were controlled using a Master-8 pulse stimulator (A.M.P.I, JRS, IL). Power output from the end of FC-MF2.5 patch cord was determined using a photodiode power sensor connected to a console (Thorlabs, NJ, USA). Mice were first given a palatable food pellet (a mini M\&M) and allowed to approach and begin eating. Stimulation was started two seconds after the beginning of food consumption. For optogenetic stimulation of NAcSh $\rightarrow \mathrm{LH}$ terminals the following paraments were used: $20 \mathrm{~Hz}, 10 \mathrm{~ms}$ pulse width, $15 \mathrm{~mW}, 30$ seconds on 30 seconds off for 5 minutes). Mice were video recorded during habituation and during the 5-minute blue light stimulation.

The latency to drop the M\&M pellet was timed using the video recordings by an observer blind to treatment. The total distance moved during photostimulation was determined using Ethovision Version 5 (Noldus XT) software. A t-test was used to compare treatment groups.

\section{Slice Electrophysiology recordings}

For electrophysiological recordings of hypothalamic slices, animals were anesthetized with $0.2 \mathrm{ml}$ ketamine $(100 \mathrm{mg} / \mathrm{mL})$ and decapitated. Brains were then rapidly removed and submerged in ice cold and oxygenated sucrose substituted artificial cerebrospinal fluid (containing in mM: 236.2 sucrose, $25 \mathrm{NaHCO}_{3}, 13.6$ glucose, $2.5 \mathrm{KCl}, 2.5 \mathrm{CaCl}_{2}, 1 \mathrm{NaH}_{2} \mathrm{PO}_{4}$ and $\left.1 \mathrm{MgCl}_{2}\right)$. Coronal slices $(250 \mu \mathrm{m})$ containing the $\mathrm{LH}$ were obtained using a vibrating microtome (Campden 7000smz) and then transferred to an oxygenated storage chamber containing artificial cerebrospinal fluid (119.4 $\mathrm{mM} \mathrm{NaCl}$ substituted for sucrose) and incubated for a minimum of 1 hour at room temperature prior to recording. Brain slices were then transferred to a recording chamber and continually superfused with oxygenated artificial cerebrospinal fluid.

Cells were visualized using infrared differential interference contrast microscopy attached onto a Laser Applied Stimulation and Uncaging electrophysiology rig (Scientifica). Whole-cell recordings were made using a Multiclamp 700B amplifier (Molecular Devices), gain of 20, digitized at $4 \mathrm{kHz}$ via NI USB-6361 (National Instruments) and recorded onto a PC running Axograph X software (Axograph). All recordings were restricted to NAcSh (Bregma 1.3 - 1.5 
$\mathrm{mm}$ ) and LH slices (Bregma -1.3 - -1.7). After obtaining the whole-cell recording configuration, series resistance and membrane resistance were monitored and only stable recordings ( $<20 \%$ changes) were included.

Optically evoked postsynaptic currents (oPSCs) were evoked by light flashes delivered from a microscope-mounted $473 \mathrm{~nm}$ LED (Thorlabs) at $20 \mathrm{~Hz}, 5 \mathrm{~ms}$ pulse width. Photocurrents were detected and captured using a sliding template method (Clements \& Bekkers, 1997) along with a minimum amplitude threshold criterion of 10 picoamps. Captured oPSCs were individually inspected and excluded from analysis if they included overlapping events or had an unstable baseline before the rise or during the decay phase of the oPSC. Data were rejected if a significant trend was evident in either oPSC amplitude or instantaneous frequency over the course of the experiment. Analyses were performed on averaged oPSCs, generated by aligning the rising phase of all accepted events. Sensitivity to the sodium channel blocker tetrodotoxin (TTX; $1 \mu \mathrm{M})$, in conjunction with 4-AP $(100 \mu \mathrm{M})$, a blocker of voltage-gated $\mathrm{K}^{+}$channels that can rescue effects of TTX on ChR2 terminal release (Petreanu et al., 2009), were used to infer whether connections from the NAcSh $\rightarrow$ orexin cells were likely poly or monosynaptic. Bath application of the $G A B A_{A}$ receptor antagonist picrotoxin $(50 \mu \mathrm{M})$ or the AMPA receptor antagonist 6-cyano-7-nitroquinoxaline-2,3-dione (CNQX; 100 $\mu \mathrm{M})$ were used as a further confirmation of inhibitory projections.

\section{Immunohistochemistry}

For validation of orexin-Cre mice: to co-label for orexin, 3 LH sections per animal were selected and incubated in an orexin-A rabbit polyclonal antibody (1:1000 anti-rabbit, Phoenix Pharmaceuticals, CA, USA) for 48 hours at room temperature. Brain sections were then washed in 0.1M PBS to rinse unbound antibody and moved to a secondary antibody (1:500, Alexa Fluor AMCA anti-rabbit; Jackson Immunoresearch, PA, USA) for 2 hours at room temperature. Tissue slices were then mounted and coverslipped using a mixture of $0.1 \mathrm{M}$ PBS and glycerol. Images of tissue sections were made using Olympus CellSens Software (version 1.3) on a microscope (Olympus BX51) at 10x objective using the green and blue wavelength filters. Virally transduced GCaMP6 cells and orexin-A labelled cells (Bregma -1.22 to -1.7) were counted using the Cell Counter add-on application in ImageJ, and analysis was undertaken by an observer blind to the treatment.

\section{Statistical analysis}

Repeated measures one-way ANOVAs were performed to compare the experimental conditions, with Dunnett's test for multiple comparisons where appropriate. Statistical significance was determined by a threshold of $\mathrm{P}<0.05$.

\section{Data and code availability}

MATLAB code used to analyze electrophysiological measures is available on request from the corresponding author.

\section{Author Contributions}

C.S.M., J.S.B., G.P.M., Z.A.A., B.A.G., C.V.D. conceived the study and designed the experiments. C.S.M. performed surgeries. C.S.M. and S.D.F. conducted fiber photometry experiments. C.S.M., A.J.P. and N.J.B. conducted optogenetic behavioral experiments. J.W.Y conducted electrophysiology experiments. C.S.M. and S.D.F. analyzed behavioral, 
bioRxiv preprint doi: https://doi.org/10.1101/2020.03.05.979468; this version posted March 6. 2020. The copyright holder for this preprint (which was not certified by peer review) is the author/funder, who has granted bioRxiv a license to display the preprint in perpetuity. It is made available under aCC-BY-NC-ND 4.0 International license.

photometry, and electrophysiology data. A.J.P. and N.J.B. performed image analysis. C.S.M., S.D.F. and C.V.D. wrote the manuscript.

\section{Declaration of Interests}

The authors declare no competing interests. 


\section{Supplemental Figures}
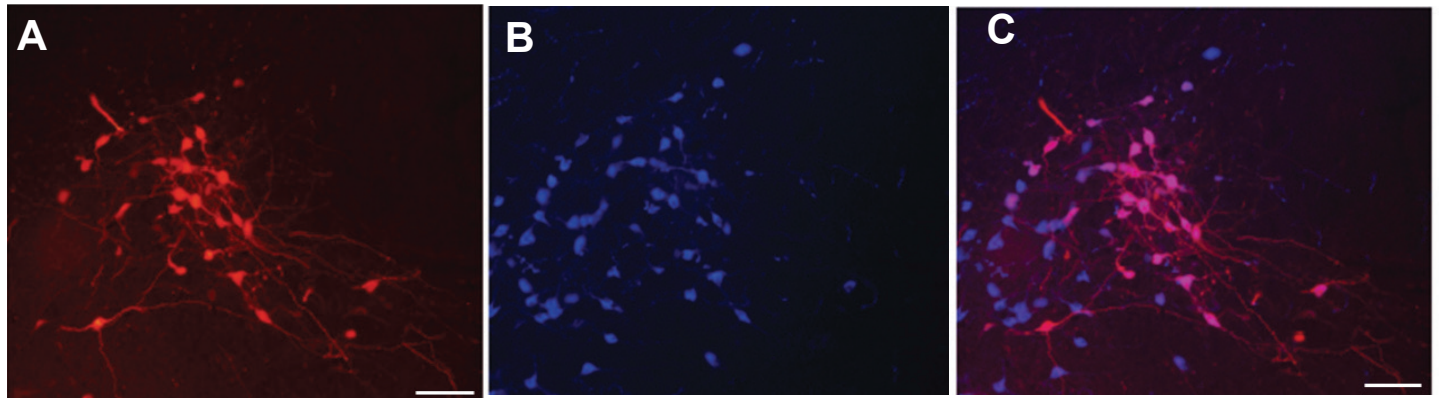

Supplemental Figure 1. Validation of h-orexin virus. To validate our h-orexin virus we used a 1:4 dilution in saline solution (A) which was later co-labelled for orexin-A (B). Colocalization of h-orexin and orexin-A labelling representing the proportion of orexin-positive $h$-orexin cells (C). Scale bars: $100 \mu \mathrm{m}$.

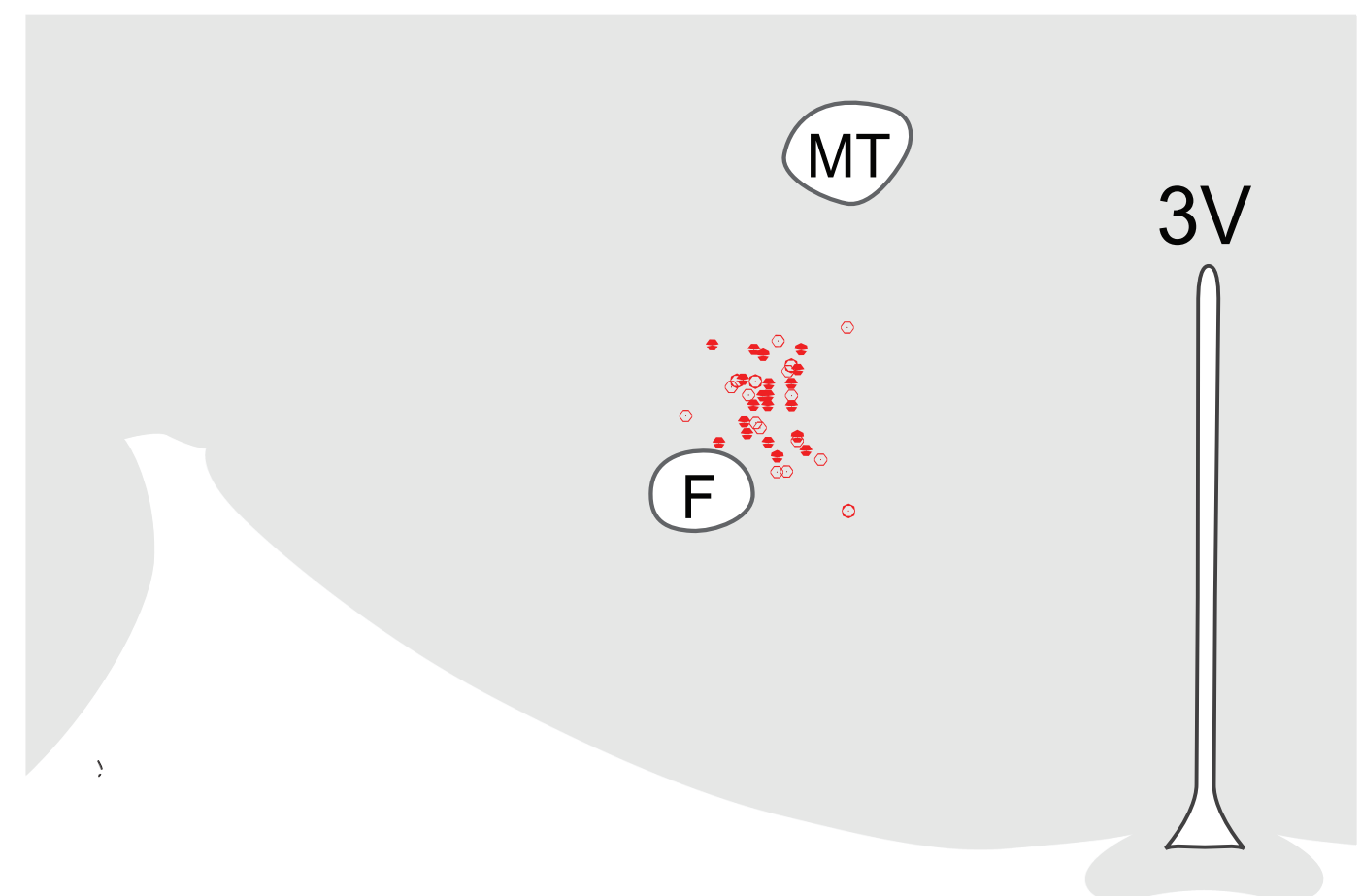

Supplemental Figure 2. Location of LH orexin cells recorded from during electrophysiology, relating to Fig. 3. 


\section{References}

Alexandre, C., Andermann, M. L., \& Scammell, T. E. (2013). Control of arousal by the orexin neurons. Current Opinion in Neurobiology, 23(5), 752-759. https://doi.org/10.1016/j.conb.2013.04.008

Bentzley, B. S., \& Aston-Jones, G. (2015). Orexin-1 receptor signaling increases motivation for cocaine-associated cues. The European Journal of Neuroscience, 41(9), 1149-1156. https://doi.org/10.1111/ejn.12866

Blais, A., Drouin, G., Chaumontet, C., Voisin, T., Couvelard, A., Even, P. C., \& Couvineau, A. (2017). Impact of Orexin-A Treatment on Food Intake, Energy Metabolism and Body Weight in Mice. PLOS ONE, 12(1), e0169908. https://doi.org/10.1371/journal.pone.0169908

Borgland, S. L., Chang, S.-J., Bowers, M. S., Thompson, J. L., Vittoz, N., Floresco, S. B., Chou, J., Chen, B. T., \& Bonci, A. (2009). Orexin A/hypocretin-1 selectively promotes motivation for positive reinforcers. The Journal of Neuroscience, 29(36), 11215-11225. https://doi.org/10.1523/jneurosci.6096-08.2009

Clements, J. D., \& Bekkers, J. M. (1997). Detection of spontaneous synaptic events with an optimally scaled template. Biophysical Journal, 73(1), 220-229. https://doi.org/10.1016/s00063495(97)78062-7

España, R. A., Plahn, S., \& Berridge, C. W. (2002). Circadian-dependent and circadian-independent behavioral actions of hypocretin/orexin. Brain Research, 943(2), 224-236. https://doi.org/10.1016/s0006-8993(02)02653-7

Ferrari, L. L., Park, D., Zhu, L., Palmer, M. R., Broadhurst, R. Y., \& Arrigoni, E. (2018). Regulation of Lateral Hypothalamic Orexin Activity by Local GABAergic Neurons. The Journal of Neuroscience, 38(6), 1588-1599. https://doi.org/10.1523/jneurosci.1925-17.2017

Georgescu, D., Zachariou, V., Barrot, M., Mieda, M., Willie, J. T., Eisch, A. J., Yanagisawa, M., Nestler, E. J., \& DiLeone, R. J. (2003). Involvement of the Lateral Hypothalamic Peptide Orexin in Morphine Dependence and Withdrawal. Journal of Neuroscience, 23(8), 3106-3111. https://doi.org/10.1523/jneurosci.23-08-03106.2003

Giardino, W. J., Eban-Rothschild, A., Christoffel, D. J., Li, S.-B., Malenka, R. C., \& Lecea, L. de. (2018). Parallel circuits from the bed nuclei of stria terminalis to the lateral hypothalamus drive opposing emotional states. Nature Neuroscience, 21(8), 1084-1095. https://doi.org/10.1038/s41593-0180198-x

Gibson, G. D., Prasad, A. A., Jean-Richard-dit-Bressel, P., Yau, J. O. Y., Millan, E. Z., Liu, Y., Campbell, E. J., Lim, J., Marchant, N. J., Power, J. M., Killcross, S., Lawrence, A. J., \& McNally, G. P. (2018). Distinct Accumbens Shell Output Pathways Promote versus Prevent Relapse to Alcohol Seeking. Neuron, 98(3), 512-520.e6. https://doi.org/10.1016/j.neuron.2018.03.033

González, J. A., Jensen, L. T., Iordanidou, P., Strom, M., Fugger, L., \& Burdakov, D. (2016). Inhibitory Interplay between Orexin Neurons and Eating. Current Biology : CB, 26(18), 2486-2491. https://doi.org/10.1016/j.cub.2016.07.013

Harris, G. C., Wimmer, M., \& Aston-Jones, G. (2005). A role for lateral hypothalamic orexin neurons in reward seeking. Nature, 437(7058), 556-559. https://doi.org/10.1038/nature04071

Hewson, A. K., Tung, L. Y. C., Connell, D. W., Tookman, L., \& Dickson, S. L. (2002). The Rat Arcuate Nucleus Integrates Peripheral Signals Provided by Leptin, Insulin, and a Ghrelin Mimetic. Diabetes, 51(12), 3412-3419. https://doi.org/10.2337/diabetes.51.12.3412

James, M. H., Charnley, J. L., Levi, E. M., Jones, E., Yeoh, J. W., Smith, D. W., \& Dayas, C. V. (2011). Orexin-1 receptor signalling within the ventral tegmental area, but not the paraventricular thalamus, is critical to regulating cue-induced reinstatement of cocaine-seeking. International Journal of Neuropsychopharmacology, 14(5), 684-690.

https://doi.org/10.1017/s1461145711000423 
Kohno, D., Gao, H.-Z., Muroya, S., Kikuyama, S., \& Yada, T. (2003). Ghrelin Directly Interacts With Neuropeptide-Y-Containing Neurons in the Rat Arcuate Nucleus: Ca2+ Signaling via Protein Kinase A and N-Type Channel-Dependent Mechanisms and Cross-Talk With Leptin and Orexin. Diabetes, 52(4), 948-956. https://doi.org/10.2337/diabetes.52.4.948

Mieda, M., Williams, S. C., Sinton, C. M., Richardson, J. A., Sakurai, T., \& Yanagisawa, M. (2004). Orexin Neurons Function in an Efferent Pathway of a Food-Entrainable Circadian Oscillator in Eliciting Food-Anticipatory Activity and Wakefulness. Journal of Neuroscience, 24(46), 1049310501. https://doi.org/10.1523/jneurosci.3171-04.2004

Nevárez, N., \& Lecea, L. de. (2018). Recent advances in understanding the roles of hypocretin/orexin in arousal, affect, and motivation. F1000Research, 7, F1000 Faculty Rev-1421. https://doi.org/10.12688/f1000research.15097.1

O'Connor, E. C., Kremer, Y., Lefort, S., Harada, M., Pascoli, V., Rohner, C., \& Lüscher, C. (2015). Accumbal D1R Neurons Projecting to Lateral Hypothalamus Authorize Feeding. Neuron, 88(3), 553-564. https://doi.org/10.1016/j.neuron.2015.09.038

Petreanu, L., Mao, T., Sternson, S. M., \& Svoboda, K. (2009). The subcellular organization of neocortical excitatory connections. Nature, 457(7233), 1142-1145. https://doi.org/10.1038/nature07709

Peyron, C., Tighe, D. K., Pol, A. N. van den, Lecea, L. de, Heller, H. C., Sutcliffe, J. G., \& Kilduff, T. S. (1998). Neurons Containing Hypocretin (Orexin) Project to Multiple Neuronal Systems. The Journal of Neuroscience, 18(23), 9996-10015. https://doi.org/10.1523/jneurosci.18-2309996.1998

Ramanathan, L., \& Siegel, J. M. (2014). Gender differences between hypocretin/orexin knockout and wild type mice: age, body weight, body composition, metabolic markers, leptin and insulin resistance. Journal of Neurochemistry, 131(5), 615-624. https://doi.org/10.1111/jnc.12840

Sakurai, T., Amemiya, A., Ishii, M., Matsuzaki, I., Chemelli, R. M., Tanaka, H., Williams, S. C., Richardson, J. A., Kozlowski, G. P., Wilson, S., Arch, J. R. S., Buckingham, R. E., Haynes, A. C., Carr, S. A., Annan, R. S., McNulty, D. E., Liu, W.-S., Terrett, J. A., Elshourbagy, N. A., ... Yanagisawa, M. (1998). Orexins and Orexin Receptors: A Family of Hypothalamic Neuropeptides and G ProteinCoupled Receptors that Regulate Feeding Behavior. Cell, 92(4), 573-585. https://doi.org/10.1016/s0092-8674(00)80949-6

Sutcliffe, J. G., \& Lecea, L. de. (2002). The hypocretins: Setting the arousal threshold. Nature Reviews Neuroscience, 3(5), 339-348. https://doi.org/10.1038/nrn808

Thorpe, A. J., Cleary, J. P., Levine, A. S., \& Kotz, C. M. (2005). Centrally administered orexin A increases motivation for sweet pellets in rats. Psychopharmacology, 182(1), 75-83. https://doi.org/10.1007/s00213-005-0040-5

Viviani, D., Haegler, P., Jenck, F., \& Steiner, M. A. (2014). Orexin neuropeptides contribute to the development and persistence of generalized avoidance behavior in the rat. Psychopharmacology, 232(8), 1383-1393. https://doi.org/10.1007/s00213-014-3769-x

Xie, X., Crowder, T. L., Yamanaka, A., Morairty, S. R., LeWinter, R. D., Sakurai, T., \& Kilduff, T. S. (2006). GABA B receptor-mediated modulation of hypocretin/orexin neurones in mouse hypothalamus. The Journal of Physiology, 574(2), 399-414. https://doi.org/10.1113/jphysiol.2006.108266

Yeoh, J. W., James, M. H., Jobling, P., Bains, J. S., Graham, B. A., \& Dayas, C. V. (2012). Cocaine potentiates excitatory drive in the perifornical/lateral hypothalamus. The Journal of Physiology, 590(16), 3677-3689. https://doi.org/10.1113/jphysiol.2012.230268

Zhang, Z.-M., Chen, S., \& Liang, Y.-Z. (2010). Baseline correction using adaptive iteratively reweighted penalized least squares. The Analyst, 135(5), 1138. https://doi.org/10.1039/b922045c 
bioRxiv preprint doi: https://doi.org/10.1101/2020.03.05.979468; this version posted March 6. 2020. The copyright holder for this preprint (which was not certified by peer review) is the author/funder, who has granted bioRxiv a license to display the preprint in perpetuity. It is made available under aCC-BY-NC-ND 4.0 International license.

Zink, A. N., Bunney, P. E., Holm, A. A., Billington, C. J., \& Kotz, C. M. (2017). Neuromodulation of orexin neurons reduces diet-induced adiposity. International Journal of Obesity, 42(4), 737-745. https://doi.org/10.1038/ijo.2017.276 